\title{
The software Photoshop clothing teaching mode under the network environment
}

\author{
Fengqin Chen ${ }^{1, \text { a }}$ \\ ${ }^{1}$ Jiangxi Institute of Fashion Technology, Jiangxi, Nanchang, 330201 \\ ${ }^{\mathrm{a}}$ email
}

Keywords: The network environment, Photoshop, clothing software, teaching mode

\begin{abstract}
This paper mainly describes the characteristics of blended learning teaching mode based on network platform. And it states that the author combined Photoshop course teaching with blended learning teaching mode. It is application -oriented. And it can improve students' autonomous learning ability and cultivate their information quality to reach superior teaching effect.
\end{abstract}

\section{Introduction}

Photoshop is one of multiple famous image processing software belonging to ADOBE Company. It is also one of current most popular software to utilize computer to process static image. It has major functions like image editing, picture synthesis, verifying color and color modulation and special effects. After multiple version improvement, current version is Photoshop CS6. It is not only perfect compatible about Vista operating system, but also supports widescreen display new layout. What's more, it has dock gathered more than twenty windows, occupation less space toolbar, multiple pictures automatic generating panorama, flexible black and white transforming, selection tool easier to adjust, intelligent filter, modified end point character and better 32 bit HDR image supporting. Thus, it totally can be sure to be a core curriculum of nationwide educational technology major, computer application major, art design major, advertisement design major and other majors.

Our school as a design college establishes Photoshop graphic design curriculum to cultivate students' software application ability, creative spirit and research ability. The author as the speaker of the curriculum actively tries to apply different teaching modes to guide students in teaching practice. And I find one mode appropriate to our students in multiple teaching modes. Then we combine computer basic education with modern educational technology to cultivate comprehensive quality. After two years trial, we finally find that blended learning teaching mode has made greatest effect in the class. The following is the discussion about teaching mode combined with practical experience in Photoshop teaching application.

\section{Fundamental of blended learning}

Blending learning has been thought to be a learning style combined online learning with face to face teaching. Essentially, blended learning is a new learning style or idea. It combines the advantage of traditional learning style with digitization or the advantage of network learning style(e-learning). In other words, we not only need to exert teachers' guidance, inspiration, leading role in monitoring teaching process, but also give full play to embody students' initiative, positive and creative. Combining with two idea and make them complement each other's advantages can obtain the best learning effect.

Although blended learning is the mixture of online learning(on-line) and face to face learning(off-line) in the form, the deep level includes the mixture of teaching mode based on different instructional theory like constructivism, behaviourism and cognitivism, the mixture of teachers' dominate activity and students' main participating, the mixture of classroom teaching and online learning, the mixture of different teaching medias. The manifestation of blended learning in traditional teaching is to apply the mode combined audio-visual media teaching mode with 
traditional classroom teaching, the combination of computer assisted instruction mode and traditional single teaching mode and the combination of students' autonomous learning mode and cooperative learning between students.

\section{Learning environment of blended learning teaching mode}

With the constant development of educational technology subject, learning environment has happened earth-shaking changes. The application of information technology based on Internet has been more and more widely in educational field. The fundamental form of blended learning teaching model is the mixture of teachers and students face to face and online learning. And network platform just breaks through the limitation of time and space, and breaks traditional classroom tuitional single mode. It has many factors like abundant resources, great sharing, great openning and great interaction. It offers virtual online learning environment for students, which makes students break the limitation of place and time to online learn, which makes students break the limitation of place and time to online learn. It can make students obtain others' help and talk with others about problems. Thus, blended learning teaching mode can be better developed based on network study environment.

Building campus network has been finished. The whole school has a superior basic network platform, and network resource is abundant. The school has bigger teaching resource database, which includes web-based teaching platform, multimedia teaching attachments, online video books, network question bank, communication forum, E-mail and chat room. And it also has thorough hardware system to support every teaching software running.

\section{Teaching practice of blended learning teaching mode in Photoshop}

Teaching method the author used in Photoshop teaching is major multiple mixture forms of oneself class teaching and students' collaborative learning and online learning based on network platform. The following is the teaching example as Photoshop teaching image composite and analyzes blended learning teaching mode based on network environment.

Ensure teaching objectives. They need to grasp basic approach of image composite. Then they need to learn to utilize Photoshop to change coverage mode. And they need to learn to use mask to implement two different images composite.

We cultivate students problem-solving ability, innovation ability, will capacity and collaboration ability, and enhance them information procession capability and exercise practical operational capacity.

Teaching environment. Teaching mainly uses multimedia network classroom, school resource library Internet.

Teaching method. Since the class emphasis is to teach how to do sectional drawing, how to use mask coverage and practice students' start work ability. Teaching mode is to adopt class example teaching mode and students' autonomous learning mode and collaboration learning mode.

Teaching process. In the multi-media classroom, the author combined with one production example in city night scene to explain about case basic thinking. Firstly, we find a fireworks picture, and then find night scene picture. We utilize Photoshop to put fireworks into night scene picture to get perfect complex effect. We told students that we mainly utilize Photoshop to change coverage mode, mask and brush to implement. Then we make operation demonstration. Students know how to change and add coverage mode by projection operation demonstration.

After class teaching demonstration, we show a few seemingly easy but ingenious artifactitious compound picture. These pictures have certain interest implication production. We told students composograph brought us wonderful point. Through the demonstration, students know the class interest, motivate study desire and lay a foundation for next do-it-yourself production. We started to create issue circumstance. We let students find themselves' favorite city night scenes on the Internet, and then they finished night scene composite graph with learnt knowledge. Finished productions upload to teaching computer production file. And then I would select better productions to issue 
school teaching website.

When students accept problems, they begin to do it themselves. They can consult basic knowledge related to composite graph in school teaching resource database. They also can search some picture material, coverage mode and mask knowledge on the Internet. Students can make discussion and communication by face to face talk or exchange field in teaching website. I encourage students to strive teachers to guide needed classmate to exercise. Teachers walk around and know students problems timely. We answer students' problems. When we find operation mislead students, we point out them timely and make individual coach for much issues individual student. If we find that there is a problem most students can not understand, we teach it again.

Before 15 minutes we end class, one student shows his production and demonstrates operation. Teacher can comment on operation steps. Students watch classmate operation and point out correct errors, accomplish knowledge conclude. When the demonstration accomplishes, teachers export some productions in the file. We grasp basic steps of composite image and learn the application of image mask and change of coverage mode, which gets class learning goal. For some having no finished production students, they can continually make online study after class and then submit production.

\section{Conclusion}

Through a few semesters teaching experiment, we make summative test result analysis the school 11 and 12 grades design speciality class. Blended learning teaching mode based on network more conform to the class practical teaching. Photoshop is application software. Practice operation is strong. Blended teaching has outstanding effect in operating skill and comprehensive ability. In the class, we adopt class teaching example and studnets' autonomous learning, collaborative learning mixture teaching mode, which would make teachers system explain and demonstrate firstly. Then students can fast autonomously grasp operation skill to finish learning task under the teacher guidance. In the meanwhile, we pay attention to offering students self-determination exercise challenge and enhance students practical operation skill training. Through the teaching mode, students' autonomous learning ability and teachers' information literacy have been improved.

Blended learning is not only a regression of learning idea, but also a screw type arising. It no longer emphasizes application of network learning environment and ignores class teaching. It no longer emphasizes student centered and ignores teachers' leading role. It no longer emphasizes constructivism and ignores other learning idea guiding function. And it no longer emphasizes network resource application and ignores video and other traditional media application. Thus, blended learning not only embodies information era character, but also envisages study traditional origin. This paper only makes preliminary discussion of blended learning teaching mode based on network environment. And it takes example of teaching practice to analyze the whole teaching process. Then it makes detail discuss for every teaching link and make analysis of teaching effect. It is only preliminary trial of Photoshop teaching reformation. In the future teaching work, I will make exploration for different subjects teaching mode.

\section{References}

[1] Kedong Li, Jianhua Zhao. The theory and application mode of blended learning, J. E-education Research, 7 (2004) 1-6.

[2] Zhaoxia Yu. Photoshop website design and application research, Shandong Normal University, 2006.

[3] Guorong Zhang. Explore and practice of task drive based on network environment in Photoshop teaching, J. Computer Knowledge and Technology, 2006(8) 221-222. 